\title{
No-CL Superstimulatory Protocol: Developing a New Superovulation Treatment Initiated in the Absence of Corpus Luteum (CL) and Compared with D1 and Traditional Superovulation in Cattle
}

\author{
Taymour M. EL-Sherry ${ }^{*}{ }^{1,2}$, Motozumi Matsui ${ }^{2}$, Katsuya Kida ${ }^{3}$, Akio Miyamoto ${ }^{4}$, \\ Gaber A. Megahed ${ }^{1}$, Shehata H. Shehata ${ }^{1}$ and Yoh-Ichi Miyake ${ }^{2}$ \\ ${ }^{1}$ Department of Theriogenology, Assiut University, Assiut, 71526, Egypt; ${ }^{2}$ Department of Clinical Veterinary Science, \\ ${ }^{3}$ Field Centre of Animal Science and Agriculture, ${ }^{4}$ Graduate School of Animal and Food Hygiene, Obihiro University of \\ Agriculture and Veterinary Medicine, Obihiro, Japan
}

\begin{abstract}
The objective of this study was to investigate the effectiveness of superovulation under a complete absence of the Corpus luteum (CL) and compare it with D1 protocol and traditional superovulation in cattle. Animals were divided into three groups as following; 1-D1-protocol: Animals $(n=7)$ were leaved to get natural ovulation (D0), then received FSH for the next 4 days of the cycle. GnRH was given $12 \mathrm{~h}$ after the last dose of FSH. 2- No-CL superovulation protocol: Animals $(\mathrm{n}=10)$ were synchronized and received PGF2 $\alpha$ at D9 or D10 then classified to two subgroups (D9-sub-group and D10-sub-group). After $36 \mathrm{~h}$, all follicles ( $\geq 5 \mathrm{~mm}$ ) were aspirated (D0). 3- Control: Animals ( $\mathrm{n}=3$ ) were submitted to the conventional superovulation protocol. Blood samples were collected daily for 13 days. Progesterone $\left(\mathrm{P}_{4}\right)$ and Estradiol $\left(\mathrm{E}_{2}\right)$ in plasma were measured by Enzyme immune assay (EIA).

The results showed that the number of growing follicles was significantly $(\mathrm{P}<0.05)$ higher in both $\mathrm{D} 9$ and D10 subgroups in comparison to the $\mathrm{D} 1$ protocol $(25.8 \pm 4.3$ and $20 \pm 1.9$ vs. $10.9 \pm 1.9$ respectively). While the number of ovulated follicle was higher in D9 sub-group than D10 sub-group, D1 protocol and control (13.8 \pm 4.4 vs. 7.6 $\pm 3.5,6.8 \pm 1.5$ and $9.7 \pm 0.9)$.
\end{abstract}

In conclusion, the superovulation protocol with complete absent of the CL produced high number of growing follicles, decreased variability and considered as a promising superovulation protocol.

Keywords: Cattle, Superovulation, CL, Estradiol, Progesterone, FSH.

\section{INTRODUCTION}

The traditional superovulation protocol was designed in the 1980 s without the current understanding of follicular dynamics in cattle. However, the using of the transrectal ultrasonography as a tool to study ovarian physiology provided information about the wave like pattern of follicular development in many species [1]. The knowledge regarding follicular wave development has been taken into account when designing regimen to control ovarian activity during superovulation. For instance, the initiation of the FSH treatment at the time of wave emergence elicited a high superovulation response [2]. Furthermore, removal of the dominant follicle by ablation [3,4] or injection of GnRH [5] increased the number of recruited follicles and synchronized the follicular wave emergence [4]. Some researchers have focused on starting the superovulation protocol at the first wave in which the wave emergence occurred at a consistent point (after ovulation) and in the absence of dominant follicle. Comparing the result of superovulation response of the first wave with second wave [6] showed no difference between the two groups. Furthermore, the use of the first

*Address correspondence to this author at the Faculty of Veterinary Medicine, Assiut University, Assiut, Egypt; Tel: 2-088-2334699;

Fax: 2-088-2-366503; E-mail: timorsherry@yahoo.com wave may be more convenient and time-sparing in superovulation programs.

The traditional superovulation protocol consist of a prolonged progesterone $\left(\mathrm{P}_{4}\right)$ priming (12-18d) with FSH initiated approximately $48 \mathrm{~h}$ before $\mathrm{P}_{4}$ withdrawal [7]. Although the $\mathrm{P}_{4}$ is important to synchronize the development of follicles, the high $\left(\mathrm{P}_{4}\right)$ level produced by the corpus luteum (CL) has reduced the diameter of dominant follicle [8] and suppressed Estradiol $\left(\mathrm{E}_{2}\right)$ secretion [9]. Similarly, the early stage of oestrous cycle (D1-protocol) has a low level of $\mathrm{P}_{4}$ which increased gradually with the developing of the cyclic CL [10].

In the present study, we developed a new superovulation protocol under a complete absence of CL and compare it with superovulation at the early stage of oestrous cycle and traditional superovulation protocol.

\section{MATERIALS AND METHODS}

This experiment was ethically approved and carried out at the Field Center of Animal Science and Agriculture, Obihiro University, Japan. The Holstein non pregnant, non lactating healthy cows were kept under the normal management program receiving maintenance ration by the staffs in this center. 


\section{Experimental Design}

1- D1 protocol $(n=7)$ : Animals in this group were leaved to get spontaneous ovulation (D0), then received 28 Armour unit (A.U) FSH on D1 for 4 successive days in the following order (D1; 5A.U, D2; 4A.U, D3; 3A.U D4; 2 A.U, twice daily, 12h interval), using (ANTRINR 10 Kawasaki Pharm. Co., Kawasaki, Japan). GnRH, analogue (Fertirelin acetate $100 \mu \mathrm{g}$; (Conceral); Nagase Pharm. Co., Osaka, Japan) was administered $12 \mathrm{~h}$ after the last dose of FSH. 2- No-CL superovulation protocol $(n=10)$ : Animals were synchronized by two injections of Cloprostenol (ESTRUMATE; 500 $\mathrm{\mu g}$ ) 11 days apart. The animals received third dose of PGF $2 \alpha$ at D9 or D10 and according to the day of injection, this group was classified to two subgroups (D9-sub and D10-sub). After $36 \mathrm{~h}$, all follicles ( $\geq 5 \mathrm{~mm}$ ) were aspirated (D0) by transvaginal ultrasound-guided follicle aspiration. For the ultrasound guidance of the aspiration needle, an ultrasound scanner (SSD-5500, ALOKA CO., Ltd., Tokyo, Japan) equipped with a $7.5 \mathrm{MHz}$ transvaginal convex transducer (UST-M15-21079, ALOKA CO., Ltd.) with an attached stainless steel needle guide was used. The FSH treatment started $24 \mathrm{~h}$ after aspiration for 4 days as the previous protocols. GnRH was given 12h after the last dose of FSH.

3- Control ( $n=3)$ : Animals were submitted to the conventional superovulation protocol. The animals get synchronized by 2 injection of PGF $2 \alpha 11$ days apart. 5 days later,
Controlled internal drug release (CIDR) was inserted with one injection of $1 \mathrm{mg}$ estradiol benzoate (EB) (Ginandol. TM., Sankyo Yell. Pharmaceutical, Tokyo, Japan). FSH injection started 5 days later and for 4 days $(6,6$ 5,5 4,4 3,3A.U). At D2, two doses of PGF $2 \alpha 12 \mathrm{~h}$ apart were given. CIDR was removed $12 \mathrm{~h}$ later and $4 \mathrm{ml}$ of $\mathrm{GnRH}$ was injected $24 \mathrm{~h}$ after that (time table for the treatment).

\section{Monitoring of Follicular Development}

Ultrasound scanning was performed by the same operator daily until the ovulation then every $48 \mathrm{~h}$ starting from D1.

To measure the follicles and CL diameter, color Doppler ultrasonography was used. The examination was performed by using the same ultrasound scanner equipped with a 7.5 $\mathrm{MHz}$ convex transducer (UST-995-7.5, Aloka Co.). The diameter of all follicles ( $\geq 3 \mathrm{~mm}$ ) through each examination was recorded except for the control groups in which the number of $\mathrm{CL}$ is only recorded.

\section{Ovulatory Response}

Ovarian response was determined by using the color signals to detect the blood flow with the velocity higher than $2 \mathrm{~mm} / \mathrm{sec}$ of the new CL. Using the color signals showed the blood boundaries of the new $\mathrm{CL}$ and so the determination of the CL number became more precise.

Table 1. The Number of Follicles and CL (Mean \pm SEM) in the Different Groups

\begin{tabular}{|c|c|c|c|c|}
\hline & \multicolumn{4}{|c|}{ Group } \\
\hline & \multirow[t]{2}{*}{ D1 protocol $(n=7)$} & \multicolumn{2}{|c|}{ NO-CL protocol $(n=10)$} & \multirow[t]{2}{*}{ Control $(n=3)$} \\
\hline & & $D 9-s u b(\mathrm{n}=4)$ & $D 10-s u b(\mathrm{n}=6)$ & \\
\hline No. of recruited follicles (D1) & $9.8 \pm 1.3$ & $17 \pm 3.8$ & $11.2 \pm 3.2$ & $\begin{array}{ll}------ \\
---\end{array}$ \\
\hline No. of follicles (D3) & $11.0 \pm 1.4^{\mathrm{b}}$ & $24.0 \pm 2.3^{\mathrm{a}}$ & $24.0 \pm 2.8^{\mathrm{a}}$ & -------- \\
\hline No of large F>8mm at (D5) & $10.0 \pm 1.9^{\mathrm{b}}$ & $25.8 \pm 4.3^{\mathrm{a}}$ & $20 \pm 1.9^{\text {ab }}$ & -------- \\
\hline
\end{tabular}

Different superscript within the row denotes significant difference $(\mathrm{P}<0.05)$.

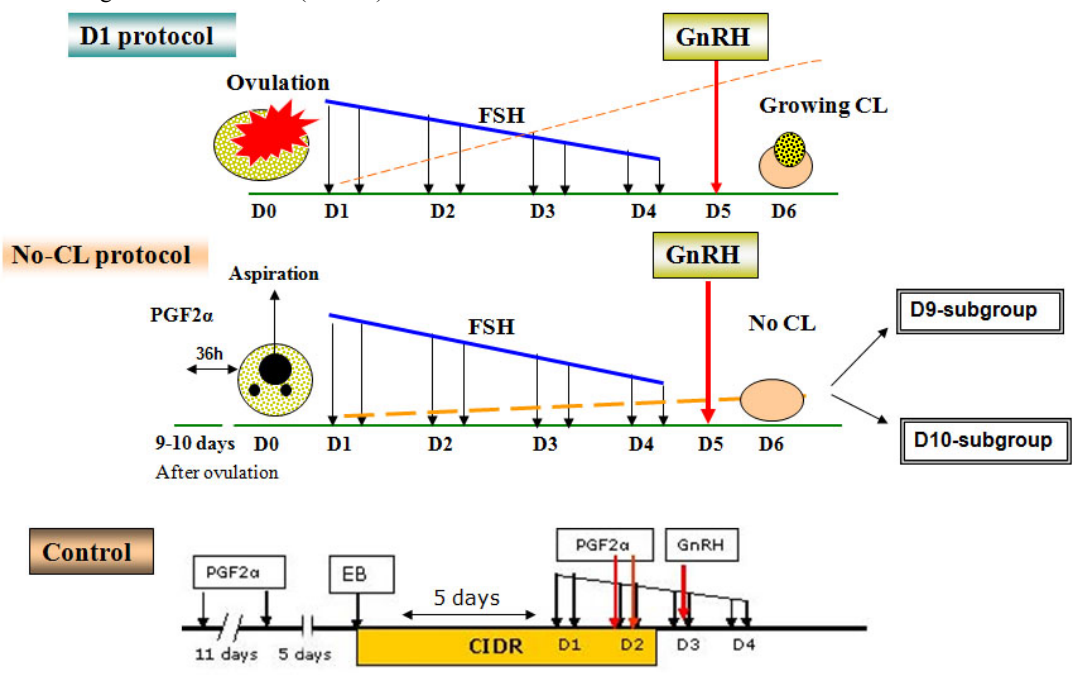

Timetable of the treatment in each group

Time table of the treatment in each group. 


\section{Blood Collection and Hormonal Determination}

Blood was collected daily starting at D1 by caudal venipuncture just after each examination by using $10 \mathrm{ml}$ heparinized tube. All tubes were immediately chilled in ice water for about $15 \mathrm{~min}$ and then centrifuged at $3000 \mathrm{rpm}$ for $20 \mathrm{~min}$ at $4^{\circ} \mathrm{C}$. The obtained plasma was decanted and stored at $-30^{\circ} \mathrm{C}$ until hormonal assay. Following extraction in diethyl ether, the concentration of $\mathrm{P}_{4}$ was determined by double- antibody enzyme immunoassays (EIA). EIA for $\mathrm{P}_{4}$ was conducted as described by [11]. The recovery rate was $87 \%$. The standard curve ranged from 0.05 to $50 \mathrm{ng} / \mathrm{ml}$, and the $\mathrm{ED}_{50}$ of the assay was $7.3 \mathrm{ng} / \mathrm{ml}$. Intra- and interassay coefficients of variability (CVs) were 2.9 and $9.3 \%$, respectively. EIA for estradiol-17 $\beta\left(\mathrm{E}_{2}\right)$ was conducted as described previously [12]. The recovery rate was $85 \%$. The standard curve ranged from 2 to $2000 \mathrm{pg} / \mathrm{ml}$ and $\mathrm{ED}_{50}$ of assay was $126.2 \mathrm{pg} / \mathrm{ml}$. Intra- and interassay coefficient of variability (CVs) were 10.4 and $15.5 \%$, respectively.

\section{Statistical Analysis}

The mean diameter of the ovulated follicles, follicular population at the time of first FSH dose (D1) and at day of GnRH injection (D5) and number of CL were compare between groups using t-test. The percentage data were analyzed using logistic regression.

The plasma concentration of $\mathrm{P}_{4}$ and $\mathrm{E}_{2}$ were analyzed by repeated measure ANOVA to determine main effects of group, day and group by day using JMP statistical software (version 5.1; SAS Institute, Cary, NC, USA 2003). The different means were significant at $\mathrm{P}<0.05$.

\section{RESULT}

The total number of follicles of No-CL protocol at D3 and D5 was significantly $(\mathrm{P}<0.05)$ higher in both $\mathrm{D} 9$ and D10 subgroups in comparison to the D1 protocol (Table 1).

Table 2. The Ovulatory Response (Mean \pm SEM) in the D9 and D10-Sub Groups

\begin{tabular}{|c|c|c|c|c|}
\hline \multirow{2}{*}{} & \multicolumn{2}{|c|}{ D9-subgroup } & \multicolumn{2}{c|}{ D10-subgroup } \\
\cline { 2 - 5 } & High response (n=3) & Low response (n=1) & High response (n=2) & Low response (n=4) \\
\hline \hline No. of CL & $17 \pm 4.2$ & 4 & $15.5 \pm 3.5$ & $2.5 \pm 1.0$ \\
\hline
\end{tabular}

Table 3. Comparison between the Diameter (Mean \pm SEM) of the Growing Follicles $(\mathrm{mm})$ During the FSH Treatment between the D9 and D10-Sub Group

\begin{tabular}{|c|c|c|c|c|}
\hline & \multicolumn{2}{|c|}{ D9-subgroup(n=4) } & \multicolumn{2}{c|}{ D10-subgroup(n=6) } \\
\cline { 2 - 5 } & High response $(\mathbf{n}=\mathbf{3})$ & Low response $(\mathbf{n}=\mathbf{1})$ & High response (n=2) & Low response (n=4) \\
\hline \hline D1 & $4.4 \pm 0.1$ & $3.8 \pm 0.1$ & $3.6 \pm 0.1$ & $6.8 \pm 2.4$ \\
\hline D3 & $8.6 \pm 0.3$ & $\mathbf{1 0 . 6} \pm \mathbf{0 . 1}$ & $8.6 \pm 0.2$ & $\mathbf{1 1 . 2} \pm \mathbf{2 . 2}$ \\
\hline D5 & $12.4 \pm 0.2$ & $15.6 \pm 0.4$ & $12.2 \pm 0.1$ & $13.2 \pm 1.5$ \\
\hline
\end{tabular}

High response (D9-subgroup)
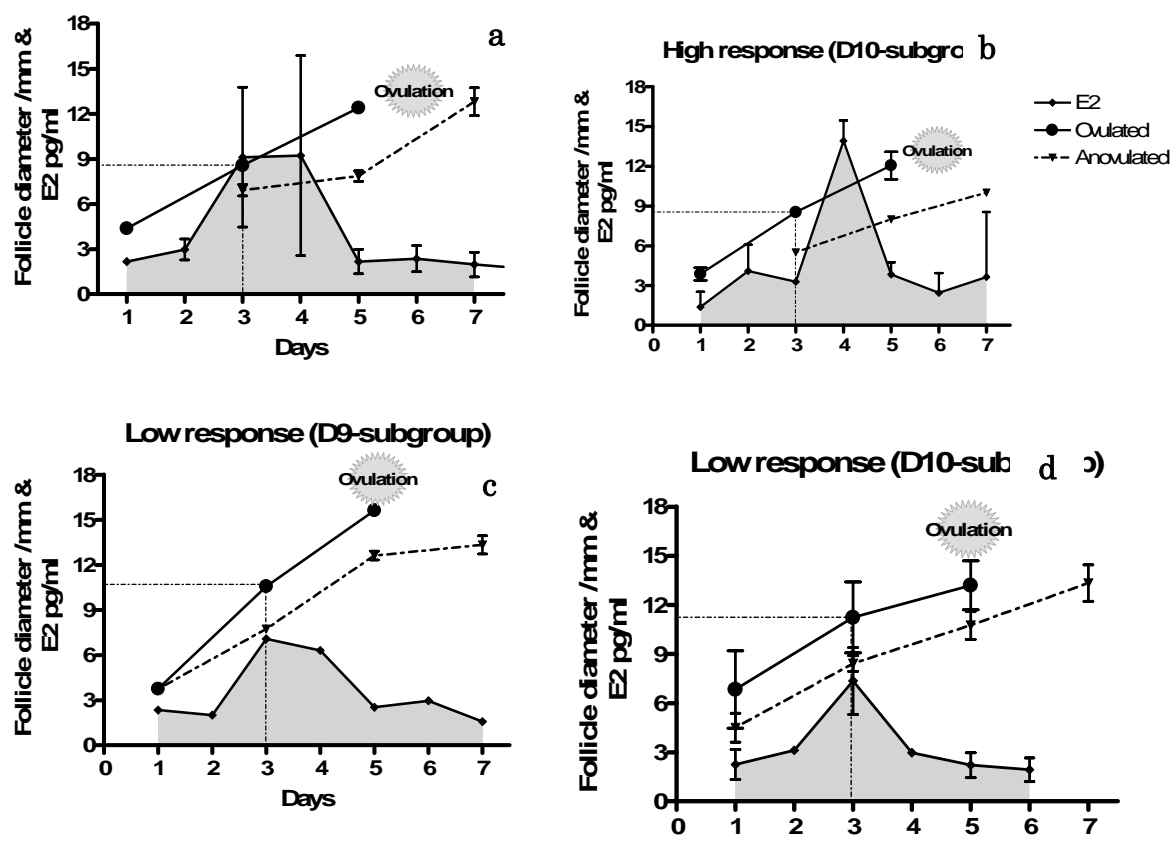

Fig. (1). Follicular growth (mean $\pm \mathrm{SEM})$ and $\mathrm{E}_{2}(\mathrm{pg} / \mathrm{ml})$ level in both high $(\mathbf{a}, \mathbf{b})$ and low $(\mathbf{c}, \mathbf{d})$ responded cows of D10 and D9 subgroup. 
Table 4. Comparison between the Level (Mean \pm SEM) of $E_{2}(\mathrm{pg} / \mathrm{ml})$ During the FSH Treatment between D9 and D10-Sub Group

\begin{tabular}{|c|c|c|c|c|}
\hline & \multicolumn{2}{|c|}{ D9-subgroup } & \multicolumn{2}{c|}{ D10-subgroup } \\
\cline { 2 - 5 } & $\begin{array}{c}\text { High response } \\
(\mathbf{n}=\mathbf{3})\end{array}$ & $\begin{array}{c}\text { Low response } \\
(\mathbf{n}=\mathbf{1})\end{array}$ & $\begin{array}{c}\text { High response } \\
(\mathbf{n}=\mathbf{2})\end{array}$ & $\begin{array}{c}\text { Low response } \\
(\mathbf{n}-\mathbf{4})\end{array}$ \\
\hline \hline D3 & $9.1 \pm 4.1$ & 7.1 & $-\cdots---$ & $7.4 \pm 2.0$ \\
\hline D4 & $9.2 \pm 6.7$ & $-\cdots-1.9 \pm 1.1$ & $13.9 \pm-$ \\
\hline
\end{tabular}

However, the mean number of ovulated follicles increased in D9 subgroup only.

Two out of six cows (33.3\%) in D10-subgroup and 3 out of 4 cows (75\%) of D9-subgroup had more than $10 \mathrm{CL}$ after treatment Table 2.

In the animals with weaker response, ovulated follicles became larger than $10 \mathrm{~mm}$ at D3 while the diameter of the non-ovulated follicles was still smaller than $8 \mathrm{~mm}$ (Table 3 ). On the other hand, in the animals with higher response, the follicular diameter was around the $8 \mathrm{~mm}$ (Fig. 1).

Another difference has been noticed, that the $\mathrm{E}_{2}$ level was higher on D3 or D4 in the animals with higher response compared with the lower response (Fig. 1, Table 4).

\section{Comparison of the Hormonal Profiles between the Different Groups}

The analysis of $\mathrm{P}_{4}$ from D0 to D6 between the three groups revealed an effect of group $(\mathrm{P}<0.01)$ and group by day $(\mathrm{P}<0.01)$. In $\mathrm{D} 1$ protocol, the $\mathrm{P}_{4}$ level was increased

\section{control protocol}

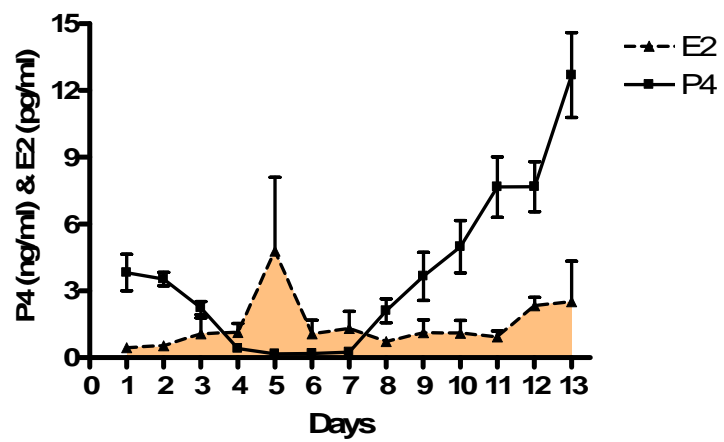

gradually form D3 concomitantly with the growth of cyclic CL. In NO-CL protocol, The $\mathrm{P}_{4}$ level was lower than $0.29 \pm$ $0.02 \mathrm{ng} / \mathrm{ml}$ for 6 days. In the control, the $\mathrm{P}_{4}$ level was high on D1 and D2 of the FSH treatment then started to decrease after the removal of the CIDR to reach the nadir at day 4. At day $7, \mathrm{P}_{4}$ start to increase without significant difference between the groups.

The analysis of $E_{2}$ from D0 to D6 revealed an effect of group $(\mathrm{P}<0.05)$ and an effect of group by day $(\mathrm{P}<0.01)$. In D1 protocol, the $E_{2}$ increased to be above $2 \mathrm{pg} / \mathrm{ml}$ from D2 to D4, and then decreased gradually (Fig. 2). On the other hand, the $\mathrm{E}_{2}$ of $\mathrm{No}-\mathrm{CL}$ protocol showed a peak on D3 or D4 (Fig. 2). Likewise, the $E_{2}$ level in control group peaked at day 5 (Fig. 2).

\section{DISCUSSION}

The increase in the number of follicles at D1 in no-CL group, confirmed the hypothesis that follicle aspiration prior to superovulation improves the ovarian response $[4,13]$.

\section{D1 protocol}

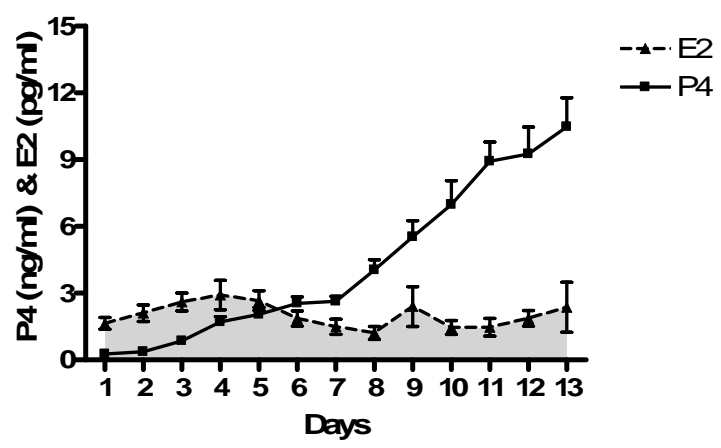

No-CL protocol (d 9 and d10 together)

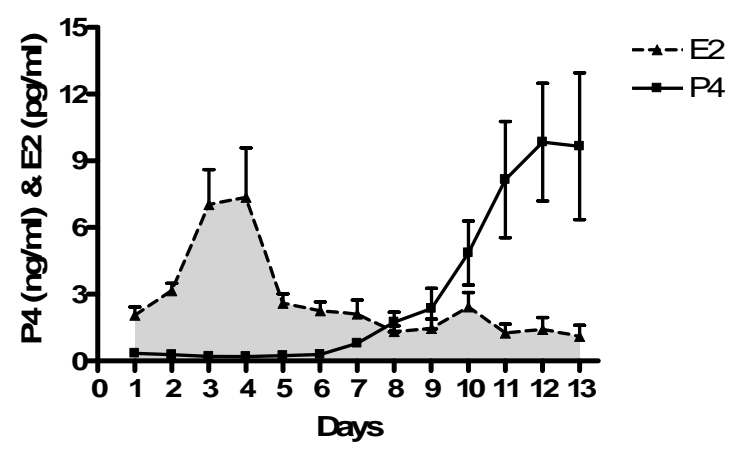

Fig. (2). Comparative changes in the plasma concentration of P4 $(\mathrm{ng} / \mathrm{ml}), \mathrm{E} 2(\mathrm{pg} / \mathrm{ml})$ in the 3 groups. Blood sample were collected daily from D1 to D13. Data shown as the mean \pm SEM of each time period. 
Empirical evidence suggested that elimination of the dominant follicle prior to superovulation induced a new follicular wave emergence which improved the ovarian response to gonadotrophic stimulation [3,4,13-15]. However, D1 protocol had the same merit of absence of the dominant follicle (D.F) after spontaneous ovulation however; the number of emerged follicles was significantly lower than the no-CL protocol. Such increase in recruited follicles at no-CL groups may be attributed to the difference of FSH secretion pattern in the 2 groups. In D1 protocol, FSH had 2 surges; preovulatory surge which associated with the ovulatory LH surge and periovulatory surge which associated with the follicle emergence [16]. In contrast, no-CL group and because of the follicle aspiration, FSH probably had one surge only, which may be higher than that of the D1 protocol.

The FSH can stimulate the follicular growth under the level of $\mathrm{P}_{4}$ but the GnRH was very important for ovulation [17]. The obtained result revealed that injection of GnRH at D5 induced a successful ovulation. This ovulation ability proved that the growing follicles of the $1^{\text {st }}$ wave had sufficient LH receptors. In the contrary, Calder, et al., [18] hypothesized that the insufficient $\mathrm{LH}$ receptors was responsible for the failure of ovulation of the first wave follicles even after injection of hCG.

In no-CL group, the aspiration of all follicles $\geq 5 \mathrm{~mm} 36 \mathrm{~h}$ after the injection of the $\mathrm{PGF}_{2 \alpha}$ and before the LH surge which estimated to be $56 \mathrm{~h}$ [19] produced no luteal tissue and subluteal $\mathrm{P}_{4}$ level. The same finding was supported by Hayashi, et al., [20] who aspirated the dominant follicle $42 \mathrm{~h}$ after the $\mathrm{PGF}_{2 \alpha}$ injection during the mid luteal phase and got no luteal tissue. The same authors added that if aspiration of the dominant follicle was post-LH surge, the aspirated follicle would grow to make a functional CL with a visible blood flow.

The ovulatory response was less variable in D9-subgroup $(75 \%)$ in comparison to D10-subgroup (33\%) and the number of ovulated follicles was increased in D9-subgroup $(13.8 \pm 4.4)$ in comparison to the other groups. In the present study, the time of $\mathrm{PGF}_{2 \alpha}$ injection and the time of follicles aspiration played a very important role in the success of the protocol. In D10-subgroup the follicle aspiration occurred at D12 (36h after $\mathrm{PGF}_{2 \alpha}$ injection) at which the dominant follicle has already lost its activity leading to the emergence of a new wave. At that time, the aspiration was difficult because many follicles were larger than $5 \mathrm{~mm}$. One of those follicles escaped from aspiration and became a dominant follicle. This escaped follicle suppressed the growth or ovulation of the other follicles. Supporting this hypothesis, it was reported that the future dominant follicle has an early development advantage than the other recruited follicles during the process of selection [21]. On the other hand, in D9-subgroup, the aspiration of the follicles occurred at D11 at which the dominant follicle was active. So it was easier to remove the dominant follicle and subordinate only. As a result, the follicles of the new wave had the same diameter.

In animals with lower response, there was a co-ordination failure of the follicular growth; one or more follicles became larger than $10 \mathrm{~mm}$ at D3. Those follicles had a negative influence on the other follicles [22] and ovulated earlier than those follicles at D4 or D5. Supporting this, animals with higher response in both D9 and D10 subgroup produced high
$E_{2}$ peak $(\geq 9 \mathrm{pg} / \mathrm{ml})$ in comparison to animals with lower response. This result showed that the growing follicles in animals with higher response were more active than those in animals with lower response. The result was supported by Ali et al., [23] who observed that the dominant follicles in growing or in early static growth phase were always $E_{2}-$ dominant.

In conclusion, the superovulation protocol with complete absent of the CL produced high number of growing follicles, decreased variability and considered as a promising superovulation protocol.

\section{CONFLICT OF INTEREST}

None declared.

\section{ACKNOWLEDGEMENT}

None declared.

\section{REFERENCES}

[1] Adams GP. Comparative patterns of follicle development and selection in ruminants. J Reprod Fertil (Suppl) 1999; 54: 17-32.

[2] Nasser LF, Adams GP, Bo GA, Mapletoft RJ. Ovarian superstimulatory response relative to follicular wave emergence in heifers. Theriogenology 1993; 40: 713-24.

[3] Amiridis GS, Tsiligianni T, Vainas E. Follicle ablation improves the ovarian response and the number of collected embryos in superovulated cows during the early stages of lactation. Reprod Domest Anim 2006; 41: 402-7.

[4] Baracaldo MI, Martinez MF, Adams GP, Mapletoft RJ. Superovulatory response following transvaginal follicle ablation in cattle. Theriogenology 2000; 53: 1239-50.

[5] Kohram H, Twagiramungu H, Bousquet D, Durocher J, Guilbault LA. Ovarian superstimulation after follicular wave synchronization with GnRH at two different stages of the estrous cycle in cattle. Theriogenology 1998; 49: 1175-86.

[6] Adams GP, Nasser LF, Bo GA, Garcia A, Del Campo MR, Mapletoft RJ. Superovulatory response of ovarian follicles of Wave 1 versus Wave 2 in heifers. Theriogenology 1994; 42: 1103-13.

[7] Alcivar AA, Maurer RR, Anderson LL. Endocrine changes in beef heifers superovulated with follicle-stimulating hormone (FSH-P) or human menopausal gonadotropin. J Anim Sci 1992; 70: 224-31.

[8] Burke CR, Mihm M, Macmillon KL, Roche JF. Some effects of prematurely elevated concentrations of progesterone on luteal and follicular characteristics during the oestrous cycle in heifers. Anim Reprod Sci 1994; 35: 27-39.

[9] Bridges PJ, Fortune JE. Characteristics of developing prolonged dominant follicles in cattle. Domest Anim Endocrinol 2003; 25: 199-214.

[10] Kaneko H, Kishi H, Watanabe G, Taya K, Shuji S, Yoshihisa H. Changes in Plasma concentrations of immunoreactive inhibin, estradiol and FSH associated with follicular waves during the estrous cycle of the cow. J Reprod Dev 1995; 41: 311-20.

[11] Miyamoto A, Okuda K, Schweigert FJ, Schams D. Effects of basic fibroblast growth factor, transforming growth factor-beta and nerve growth factor on the secretory function of the bovine corpus luteum in vitro. J Endocrinol 1992; 135: 103-14.

[12] Wijayagunawardane MP, Miyamoto A, Cerbito WA, Acosta TJ, Takagi M, Sato K. Local distributions of oviductal estradiol, progesterone, prostaglandins, oxytocin and endothelin-1 in the cyclic cow. Theriogenology 1998; 49: 607-18.

[13] Bergfelt DR, Bo GA, Mapletoft RJ, Adams GP. Superovulatory response following ablation-induced follicular wave emergence at random stages of the oestrous cycle in cattle. Anim Reprod Sci 1997; 49: 1-12.

[14] Grasso F, Guilbault LA, Roy GL, Lussier JG. Ultrasonographic determination of ovarian follicular. Development in superovulated 
heifers pretreated with FSH-P at the beginning of the estrous cycle. Theriogenology 1989; 31: 1209-20.

[15] Shaw DW, Good TE. Recovery rates and embryo quality following dominant follicle ablation in superovulated cattle. Theriogenology 2000; 53: 1521-8.

[16] Haughian JM, Ginther OJ, Kot K, Wiltbank MC. Relationships between FSH patterns and follicular dynamics and the temporal associations among hormones in natural and GnRH-induced gonadotropin surges in heifers. Reproduction 2004; 127: 23-33.

[17] Binelli M, Thatcher WW, Mattos R, Baruselli PS. Antiluteolytic strategies to improve fertility in cattle. Theriogenology 2001; 56: 1451-63.

[18] Calder M, Rajamahendran R. Follicular growth, ovulation and embryo recovery in dairy cows given FSH at the beginning or middle of the estrous cycle. Theriogenology 1992; 38: 1163-74.

[19] Gengenbach DR, Butendieck N, Riek PM, Scipioni RL, Oltenacu EB, Foote RH. Controlled superovulation in dairy heifers using prostaglandin F2alpha and pregnant mare serum gonadotropin. J Anim Sci 1978; 46: 1293-9.

[20] Hayashi KG, Matsui M, Acosta TJ, Kida K, Miyamoto A. Effect of the dominant follicle aspiration before or after luteinizing hormone surge on the corpus luteum formation in the cow. J Reprod Dev 2006; 52: 129-35.

[21] Ginther OJ, Kot K, Kulick LJ, Wiltbank MC. Emergence and deviation of follicles during the development of follicular waves in cattle. Theriogenology 1997; 48: 75-87.

[22] Armstrong DG, Webb R. Ovarian follicular dominance: the role of intraovarian growth factors and novel proteins. Rev Reprod 1997; 2: $139-46$.

[23] Ali A, Lange A, Gilles M, Glatzel PS. Morphological and functional characteristics of the dominant follicle and corpus luteum in cattle and their influence on ovarian function. Theriogenology 2001; 56: 569-76.

(C) EL-Sherry et al.; Licensee Bentham Open.

This is an open access article licensed under the terms of the Creative Commons Attribution Non-Commercial License (http: //creativecommons.org/licenses/by$\mathrm{nc} / 3.0 /$ ), which permits unrestricted, non-commercial use, distribution and reproduction in any medium, provided the work is properly cited 